\title{
LOSS OF NORADRENALINE TRANSPORTER SITES IN FRONTAL CORTEX OF RATS WITH ACUTE (ISCHEMIC) LIVER FAILURE
}

\author{
Adrianna Michalak, Christopher Rose, Roger F. Butterworth \\ Neuroscience Research Unit, Centre Hospitalier de l'Universite de Montreal (CHUM), Campus Saint-Luc, 1058 St. Denis \\ Street, Montreal,Quebec, Canada H2X3J4
}

Received 12 January 2000; received in revised form 27 March 2000; accepted 28 March 2000

\section{ABSTRACT}

There is increasing evidence that central noradrenaline (NA) transport mechanisms are implicated in the central nervous system complications of acute liver failure. In order to assess this possibility, binding sites for the high affinity NA transporter ligand $\left[{ }^{3} \mathrm{H}\right]$-nisoxetine were measured by quantitative receptor autoradiography in the brains of rats with acute liver failure resulting from hepatic devascularization and in appropriate controls. In vivo microdialysis was used to measure extracellular brain concentrations of NA. Severe encephalopathy resulted in a significant loss of $\left[{ }^{3} \mathrm{H}\right]$-nisoxetine sites in frontal cortex and a concomitant increase in extracellular brain concentrations of NA in rats with acute liver failure. A loss of transporter sites was also observed in thalamus of rats with acute liver failure. This loss of NA transporter sites could result from depletion of central NA stores due to a reserpine-like effect of ammonia which is known to accumulate to millimolar concentrations in brain in ischemic liver failure. Impaired NA transport and the consequent increase in synaptic concentrations and increased stimulation of neuronal and astrocytic noradrenergic receptors could be implicated in the pathogenesis of the encephalopathy and brain edema characteristic of acute liver failure.

\section{Keywords}

$\left[{ }^{3} \mathrm{H}\right]$-nisoxetine; Noradrenaline transporter; Acute liver failure; Cerebral cortex; Hepatic encephalopathy; Hepatic coma; Brain edema; Ammonia

\section{INTRODUCTION}

Accumulating evidence suggests that central noradrenergic mechanisms may be implicated in the pathogenesis of the central nervous system complications of acute liver failure. Studies in several animal models of acute liver failure including hepatectomy (Hadesman et al., 1995, Tyce and Owen, 1978 and Herlin et al., 1983), liver devascularization (Murakami et al., 1992) and thioacetamide-induced liver injury (Yurdaydin et al., 1990) in the rat have consistently shown decreases in brain tissue concentrations of noradrenaline (NA). Moreover, hepatectomy results in increased NA release in ventriculocisternal perfusates (McKinzie et al., 1996) and in vivo microdialysis studies have shown that liver devascularization results in increased extracellular brain concentrations of NA as a function of the severity of encephalopathy (Michalak et al., 1998). These latter two findings could be the consequence of impaired high affinity uptake of NA into neural cells. The present study, therefore, was initiated to assess the integrity of high affinity NA transport sites in relation to extracellular NA concentrations in the brains of rats with acute liver failure due to hepatic devascularization.

Michalak, A., Rose, C. \& Butterworth, R.F., 2001. Loss of noradrenaline transporter sites in frontal cortex of rats with acute (ischemic) liver failure. Neurochemistry International, 38(1), p.25-30. 


\section{MATERIALS AND METHODS}

\subsection{Surgical techniques}

Male Sprague-Dawley rats (Charles River, St. Constant, Que., Canada) weighing 175-200 g at the time of surgery, were anesthetized with halothane, and an end-to-side portacaval anastomosis was performed as previously described (Michalak et al., 1996). The inferior vena cava was partially clamped, and an elliptical piece of vein was removed. The portal vein was ligated, cut and an end-to-side anastomosis (shunt: $\mathrm{SH}$ ) was performed under a dissecting microscope, according to the guidelines of Lee and Fisher (1961). Total surgery time was $\sim 15 \mathrm{~min}$. Sham-operated animals (matched for weight) were similarly anesthetized and, following laparotomy, the inferior vena cava and portal vein were clamped for 15 min (sham: SM). After surgery, the animals had free access to standard laboratory food and water. All rats were housed under constant conditions of temperature, humidity and light cycles.

All experiments were in accordance with the Principles of the Guide for the Care and Use of Experimental Animals, vol. 2, 1984, of the Canadian Council on Animal Care, Ottawa, and the Guiding Principles for Research Involving Animals and Humans (Recommendations from the Declaration of Helsinki) approved by the Council of the American Physiological Society.

\subsection{Microdialysis}

$24 \mathrm{~h}$ after portacaval shunt or laparotomy, an intracerebral guide cannula was implanted. All animals were anesthetized (halothane), placed in a stereotaxic frame (David Kopf Instruments, Tujunga, CA) and a disposable plastic/siliconized intracerebral guide cannula was inserted to the required depth through the burr hole drilled in the skull (coordinates: +3.2 $\mathrm{mm}$ [sagittal], $-1.5 \mathrm{~mm}$ [lateral], and $-2.5 \mathrm{~mm}$ [depth] relative to the bregma (Paxinos and Watson, 1982)). The guide cannula was closed with a dummy probe and secured in place with dental acrylic. Total surgery time was $\sim 15$ min. Throughout the surgical procedure, the temperature of animals was maintained at $37^{\circ} \mathrm{C}(\mathrm{CMA} / 150$ temperature controller). Following recovery from anesthesia, rats were maintained in microdialysis chambers (CMA/120 system for freely-moving animals) with free access to rat chow and water.

$24 \mathrm{~h}$ after intracerebral guide cannula implantation (i.e., $48 \mathrm{~h}$ after shunt or sham surgery), rats were reanesthetized (halothane) and subjected to hepatic artery ligation (HAL) or laparotomy (SM). The dummy probe was removed from the intracerebral guide cannula and a microdialysis probe (CMA/12: $2 \mathrm{~mm}$ long, $0.5 \mathrm{~mm}$ diameter) was inserted into frontal cortex of freely-moving animals. Aortic and peritoneal catheters were implanted in all animals for arterial glucose monitoring, and $5 \%$ glucose (or $0.9 \% \mathrm{NaCl}$ for control animals) was administered as needed.

Four groups of rats were thus created: liver ischemia (SH + HAL) and the three obligate control groups (SH + SM, SM + $\mathrm{HAL}, \mathrm{SM}+\mathrm{SM}$ ). Separate groups of rats were used for microdialysis and autoradiographic studies. Animals for the autoradiographic study were treated as described earlier without the intracerebral guide cannula implantation. All animals were evaluated every 30 min following the second surgery.

\subsection{Measurement of NA in microdialysates}

NA concentrations were measured at precoma and coma stages of encephalopathy in acute liver failure rats and at equivalent time points in microdialysates (described earlier). NA concentrations were measured by HPLC with electrochemical detection as previously described (Michalak et al., 1998).

\section{4. $\left[{ }^{3} \mathrm{H}\right]$-nisoxetine autoradiography}

Rats were killed by decapitation and brains rapidly removed and placed in iced propanol then stored at $-70^{\circ} \mathrm{C}$ until sectioning. Sagittal sections of brains from the four groups of animals described earlier were sectioned at $20 \mu \mathrm{m}$, mounted on gelatin-coated slides and stored at $-20^{\circ} \mathrm{C}$ until use. For determination of NA transporter sites, sections were incubated with $\left[{ }^{3} \mathrm{H}\right]$-nisoxetine ( $3 \mathrm{nM}$ ) in Tris buffer essentially as previously described (Bauer and Tejani-Butt, 1992). Non-specific binding was assessed by inclusion of $1 \mu \mathrm{M}$ mazindol. Following incubation, sections were washed $(\times 3)$ with ice-cold buffer, then water $(\times 2)$, dried and apposed to $\left[{ }^{3} \mathrm{H}\right]$-sensitive film for 4 weeks. Densitometric analyses of the films were performed

Michalak, A., Rose, C. \& Butterworth, R.F., 2001. Loss of noradrenaline transporter sites in frontal cortex of rats with acute (ischemic) liver failure. Neurochemistry International, 38(1), p.25-30. 
using an image analyzer (MCID system, St. Catherines, Ont., Canada). Specific binding was calculated as the difference between specific and non-specific binding. $\left[{ }^{3} \mathrm{H}\right]$-standards were used to convert optical density measurements to binding sites densities expressed as $\mathrm{pmol} / \mathrm{g}$ tissue.

\subsection{Statistical analyses}

Data are expressed as mean \pm SEM values from at least five animals per group. Differences were compared using one-way ANOVA (Tukey-Kramer multiple comparisons test) and a $\boldsymbol{p}$ value of $<0.05$ was considered significant.

\section{RESULTS}

Rats with hepatic devascularization manifested a reproducible sequence of neurological impairment which progressed through diminished spontaneous activity followed by loss of righting ability (defined as the precoma stage) and ultimately loss of corneal reflex (coma). Rats from the three control groups showed no such neurological deterioration.

A typical autoradiogram showing $\left[{ }^{3} \mathrm{H}\right]$-nisoxetine sites in a mid-sagittal section from a control animal is shown in Fig. 1.

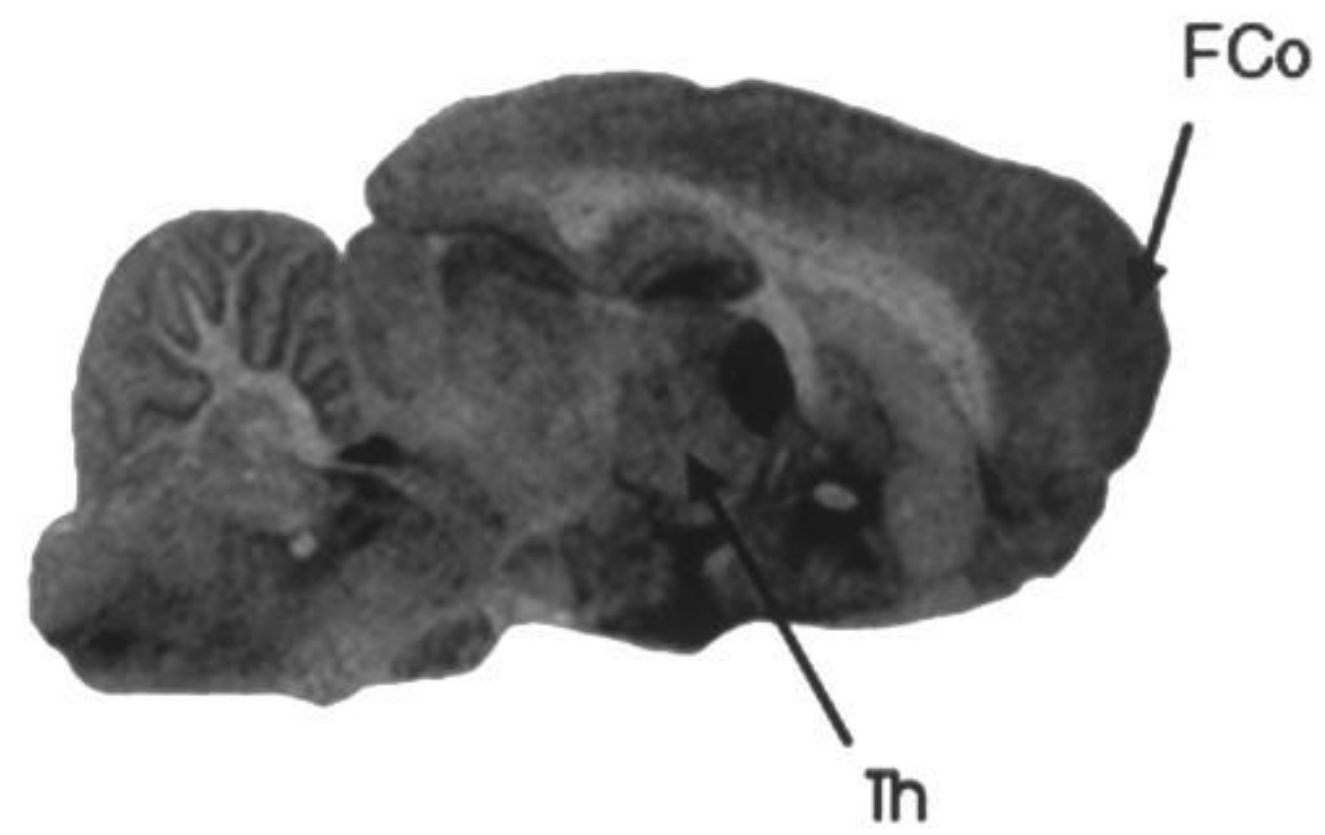

Fig. 1. Representative autoradiogram of $\left[{ }^{3} \mathrm{H}\right]$-nisoxetine binding sites to a sagittal section of normal rat brain. Note the relative uniform distribution of binding sites throughout cortical and sub-cortical regions. FCo: frontal cortex; Th: thalamus.

Of particular note was the relatively high densities of $\left[{ }^{3} \mathrm{H}\right]$-nisoxetine sites in dentate gyrus of the hippocampus as well as in thalamus and hypothalamus. This distribution of $\left[{ }^{3} \mathrm{H}\right]$-nisoxetine sites in control brains was comparable to that previously published by others (Bauer and Tejani-Butt, 1992).

At coma stages of encephalopathy in rats with acute liver failure, there was a significant loss of $\left[{ }^{3} \mathrm{H}\right]$-nisoxetine sites in frontal cortex and thalamus (Table 1). 
Table 1. Quantitative distribution of $\left[{ }^{3} \mathrm{H}\right]$-nisoxetine binding sites in brain of rats with ischemic liver failure (coma stage) and of rats from the three control groups ${ }^{\mathrm{a}}$

\begin{tabular}{|c|c|c|c|c|}
\hline \multirow[t]{3}{*}{ Brain region } & \multicolumn{4}{|c|}{$\left[{ }^{3} \mathrm{H}\right]$-nisoxetine binding sites $(\mathrm{pmol} / \mathrm{g})$} \\
\hline & \multicolumn{3}{|l|}{ Controls } & \multirow{2}{*}{$\frac{\text { Acute liver failure }}{\mathrm{SH}+\mathrm{HAL}}$} \\
\hline & $\mathrm{SM}+\mathrm{SM}$ & $\mathrm{SM}+\mathrm{HAL}$ & $\mathrm{SH}+\mathrm{SM}$ & \\
\hline Cortex & $36.2 \pm 1.58$ & $39.4 \pm 1.70$ & $41.9 \pm 1.88$ & $40.5 \pm 1.97$ \\
\hline Frontal & $39.6 \pm 2.46$ & $39.8 \pm 3.39$ & $43.5 \pm 4.43$ & $27.7 \pm 2.73 *$ \\
\hline Frontoparietal & $33.2 \pm 1.57$ & $41.4 \pm 1.51$ & $38.5 \pm 2.55$ & $43.4 \pm 2.41$ \\
\hline Anterior cingulate & $31.0 \pm 2.13$ & $34.2 \pm 3.96$ & $32.6 \pm 3.45$ & $33.9 \pm 2.44$ \\
\hline Posterior cingulate & $43.6 \pm 3.94$ & $47.9 \pm 4.19$ & $45.1 \pm 3.24$ & $46.9 \pm 4.61$ \\
\hline Hippocampus & $46.4 \pm 5.42$ & $48.1 \pm 5.55$ & $53.5 \pm 5.93$ & $55.1 \pm 5.12$ \\
\hline Dentate gyrus & $97.8 \pm 5.50$ & $106 \pm 5.01$ & $114 \pm 5.76$ & $96.4 \pm 3.05$ \\
\hline Subiculum & $21.3 \pm 1.37$ & $23.7 \pm 3.69$ & $26.5 \pm 2.49$ & $31.2 \pm 3.37$ \\
\hline Thalamus & $61.3 \pm 2.41$ & $59.6 \pm 4.70$ & $65.2 \pm 2.84$ & $39.9 \pm 2.18 *$ \\
\hline Hypothalamus & $87.7 \pm 5.82$ & $80.8 \pm 3.50$ & $73.9 \pm 5.48$ & $91.2 \pm 4.88$ \\
\hline Inferior colliculus & $30.8 \pm 2.05$ & $36.9 \pm 4.32$ & $36.6 \pm 4.43$ & $42.3 \pm 3.42$ \\
\hline Accumbens nucleus & $9.81 \pm 0.67$ & $11.0 \pm 0.44$ & $13.0 \pm 1.49$ & $13.1 \pm 1.1$ \\
\hline Cerebellum & $24.6 \pm 2.94$ & $27.2 \pm 2.90$ & $28.3 \pm 1.74$ & $25.2 \pm 2.08$ \\
\hline
\end{tabular}

a Data shown represent mean \pm SEM of duplicate determination from five rats per treatment group. Values significantly different from control groups indicated by $* \mathrm{p}<0.05$ by Analysis of Variance and post-hoc Tukey-Kramer Test. SM: sham-operated; SH: portacaval-shunted; HAL: hepatic artery ligation.

Measurement of extracellular (microdialysate) concentrations of NA in frontal cortex of rats with acute liver failure revealed a significant (46\%) increase at coma stages of encephalopathy (Table 2).

Table 2. Extracellular (microdialysate) concentrations of NA in frontal cortex of rats with acute liver failure at precoma and coma stages of encephalopathy ${ }^{a}$

\section{Treatment group NA concentration $(\mathrm{pg} / 20 \mu \mathrm{l})$}

\begin{tabular}{|c|c|c|c|}
\hline & & precoma stage $(6 \mathrm{~h})$ & coma stage \\
\hline \multirow[t]{3}{*}{ Controls } & sham/sham & $8.10 \pm 0.92$ & $7.64 \pm 0.90$ \\
\hline & sham/hal & $8.04 \pm 0.77$ & $9.06 \pm 0.74$ \\
\hline & pcs/sham & $10.09 \pm 0.68$ & $10.51 \pm 0.82$ \\
\hline Acute liver failure & pcs/hal & $10.02 \pm 0.44$ & $14.67 \pm 1.90 *$ \\
\hline
\end{tabular}

a Data shown represent mean \pm SEM of duplicate determinations from five rats per treatment group NA: noradrenaline. Values significantly different from control groups indicated by $* \mathrm{p}<0.05$ by Analysis of Variance with post-hoc Tukey-Kramer Test.

Michalak, A., Rose, C. \& Butterworth, R.F., 2001. Loss of noradrenaline transporter sites in frontal cortex of rats with acute (ischemic) liver failure. Neurochemistry International, 38(1), p.25-30. 


\section{DISCUSSION}

The NA transporter is an antidepressant-sensitive electrogenic transporter located on the plasma membrane of noradrenergic neurons (Lorang et al., 1994). It is responsible for removal of NA from the extracellular milieu of brain via an iondependent transport process (Harder and Bonisch, 1985) and, in this way, terminates the action of NA in the synapse. The study of NA transporter regulation is nowadays facilitated by the availability of the high affinity ligand [ $\left.{ }^{3} \mathrm{H}\right]$-nisoxetine which binds to a single class of sites in the rat brain (Tejani-Butt, 1992).

Results of the present study reveal a selective loss of $\left[{ }^{3} \mathrm{H}\right]$-nisoxetine sites in frontal cortex and thalamus at coma stages of encephalopathy in rats with acute liver failure. The finding of decreased transporter sites in frontal cortex of rats with acute liver failure due to hepatic devascularization offers a cogent explanation for the findings in a previous (and the present) study of increased NA concentrations in brain extracellular fluid of these animals at coma stages of encephalopathy (Michalak et al., 1998). Similar mechanisms could be implicated in hepatectomized rats in which significant increases of NA were described in ventriculocisternal perfusates (McKinzie et al., 1996). Whether or not the loss of thalamic transporter sites leads to increased extracellular NA awaits further studies.

The mechanism whereby acute liver failure results in down-regulation of NA transporter sites is not known. One possibility could involve NA itself. Previous studies reveal that treatment of rats with monoamine oxidase inhibitors, which results in increased intracellular NA, leads to increased NA transporter sites (Lee et al., 1983) whereas depletion of brain NA following reserpine administration leads to reduced NA transporter sites. It is of interest in this regard that acute liver failure in both hepatectomized and liver devascularized rats results in decreased brain NA concentrations (Tyce and Owen, 1978, Herlin et al., 1983, Murakami et al., 1992 and Hadesman et al., 1995), suggesting that the decreased transporter sites could be the consequence of a depletion of intracellular stores of NA in the brains of these animals. Furthermore, depletion of monoamine stores has previously been demonstrated following exposure of rat brain synaptosomes to millimolar concentrations of ammonia (Erecinska et al., 1987), similar to that reported in the brains of rats with ischemic liver failure (Swain et al., 1992).

Alterations in the synaptic availability of NA has been shown to contribute to neuropsychiatric disorders and encephalopathy. For example, evidence of altered central noradrenergic function has been described in patients with endogenous depression (Lechin et al., 1995) and drugs which bind to and inhibit the NA transporter are effective antidepressants (Barker and Blakely, 1995). Decreased brain concentrations of NA have also been described in the forebrain of rats with experimental septic encephalopathy (Kadoi et al., 1996). Treatment of cirrhotic patients with the adrenergic antagonist propranolol may precipitate encephalopathy in these patients (Tarver et al., 1983 and Weisner , 1986) and while this latter phenomenon has generally been attributed to a peripheral action of propranolol, central adrenergic mechanisms cannot be excluded. Administration of noradrenergic receptor antagonists to experimental animals results in delayed acquisition of motor tasks (Heron et al., 1996). A previous study showed a selective loss of $\alpha$ and $\beta$ noradrenergic receptor sites in brains of rats with acute liver failure (Michalak et al., 1998) where loss of adrenergic sites was restricted to frontal cortex and thalamus, brain regions shown, in the present study, to express decreased amounts of NA transporter sites in acute liver failure. Together, these findings suggest that acute liver failure may result in a deficit in central NA synaptic regulation. Such changes could be implicated in the neuropsychiatric and cognitive symptoms characteristic of hepatic encephalopathy in patients with acute liver failure.

The hepatic devascularized rat manifests severe brain edema at coma stages of encephalopathy (Blei et al., 1992). Brain edema in these animals, as in human acute liver failure, is cytotoxic in nature and is characterized by cytoplasmic swelling of astrocytic processes (Norenberg, 1994 and Ganz et al., 1989). Such alterations in astrocyte morphology could also be the consequence of altered NA transport and receptor function. Astrocytes express noradrenergic receptors both in vitro and in situ (Shao and Sutin, 1992) and cortical astrocytes in vitro express $\left[{ }^{3} \mathrm{H}\right]$-nisoxetine binding sites which are significantly reduced by exposure to ammonia in concentrations equivalent to those encountered in brain in acute liver failure (Hazell and Butterworth, unpublished data). Exposure of cultured cortical astrocytes to these concentrations of ammonia leads to significant cell swelling (Norenberg, 1987). A previous study showed that depletion of brain NA by 6-hydroxydopamine administration resulted in significant brain edema in experimental ischemic rats (Kobayashi et al., 1990) and earlier studies in several animal models of acute liver failure reveal similarly decreased brain tissue concentrations of NA (Hadesman et al., 1995, Murakami et al., 1992 and Yurdaydin et al., 1990). Together with the results of the present study, these findings suggest that alterations of NA transport may be implicated in the pathogenesis of brain edema in acute liver failure. Further studies are required in order to assess this possibility.

Michalak, A., Rose, C. \& Butterworth, R.F., 2001. Loss of noradrenaline transporter sites in frontal cortex of rats with acute (ischemic) liver failure. Neurochemistry International, 38(1), p.25-30. 


\section{ACKNOWLEDGEMENTS}

The authors are grateful to D.D. Roy for her secretarial assistance and to the Medical Research Council of Canada for financial support. Adrianna Michalak was a recipient of a postdoctoral research fellowship from the Canadian Association for the Study of the Liver.

\section{REFERENCES}

E.L. Barker, R.D. Blakely Norepinephrine and serotonin transporters. Molecular targets of antidepressant drugs F.E. Bloom, D.J. Kupfer (Eds.), Psychopharmacology. A Fourth Generation of Progress, Raven Press, New York (1995), pp. 321-333

M.E. Bauer, S.M. Tejani-Butt Effects of repeated administration of desipramine or electroconvulsive shock on norepinephrine uptake sites measured by ${ }^{3} \mathrm{H}$-nisoxetine autoradiography Brain Res., 82 (1992), pp. 208-214

Blei, R. Omary, R.F. Butterworth Animal models of hepatic encephalopathies A. Boulton, G.B. Baker, R.F. Butterworth (Eds.), Animal Models of Neurological Disease II, Neuromethods 22, Humana Press, Clifton, NJ (1992), pp. 183-222

M. Erecinska, A. Pastuszko, D.F. Wilson, D. Nelson Ammonia-induced release of neurotransmitters from rat brain synaptosomes: differences between the effects on amines and amino acids J. Neurochem., 49 (1987), pp. 1258-1265

R. Ganz, M. Swain, P. Traber, M. Dalcanto, R.F. Butterworth, A.T. Blei Ammonia-induced swelling of rat cerebral cortical slices: implications for the pathogenesis of brain edema in acute hepatic failure Metab. Brain Dis., 4 (1989), pp. 213-223

R. Hadesman, R.H. Wiesner, V.L.W. Go, G.M. Tyce Concentrations of 3,4-dihydroxyphenylalanine and catecholamines and metabolites in brain in an hepatic model of hepatic encephalopathy J. Neurochem., 65 (1995), pp. 1166-1175

R. Harder, H. Bönisch Effects of monovalent ions on the transport of norepinephrine across the plasma membrane of neuronal cells (PC-12 cells) J. Neurochem., 45 (1985), pp. 1154-1162

P.M. Herlin, J.H. James, C.A. Hachbauer, J.E. Fisher Effect of total hepatectomy and administration of branched-chain amino acids on regional norepinephrine, dopamine, and amino acids in rats brain Annals of Surgery, 198 (1983), pp. 172-177

C. Heron, T.J. Gould, P. Bickford Acquisition of a runway motor learning task is impaired by a beta adrenergic antagonists in F334 rat Behav. Brain Res., 78 (1996), pp. 23-241

Y. Kadoi, S. Saito, F. Kunimoto, T. Imai, T. Fujita Impairment of the brain beta-adrenergic system during experimental endotoxemia J. Surg. Res., 61 (1996), pp. 496-502

H. Kobayashi, M. Hayashi, Y. Handa, Y. Noguchi, H. Kawano, M. Kabuto Role of adrenergic activity in ischemic brain edema Adv. Neurol., 52 (1990), pp. 127-132

F. Lechin, B. van der Dijs, B. Orozco, M.E. Lechin, S. Baez, A.E. Lechin, I. Rada, E. Acosta, L. Arocha, V. Jimenez Plasma neurotransmitters, blood pressure, and heart rate during supine-resting, orthostasis, and moderate exercise conditions in major depressed patients Biol. Psychiatry, 38 (1995), pp. 166-173

S.H. Lee, B. Fisher Portacaval shunt in rat Surgery, 50 (1961), pp. 668-672

C.-M. Lee, J.A. Javitch, S.H. Snyder Recognition sites for norepinephrine uptake: regulation by neurotransmitter Science, 220 (1983), pp. 626-629

D. Lorang, S.G. Amara, R.B. Simerly Cell-type-specific expression of catecholamine transporters in the rat brain J. Neurosci., 14 (1994), pp. 4903-4914

S.L. McKinzie, D.L. Hammond, C. Grabau, G.M. Tyce Releases of norepinephrine and dopamine in vestriculocisternal perfusions in hepatectomized and laparotomized rats J. Neurochem., 66 (1996), pp. 569-578

Michalak, A., Rose, C. \& Butterworth, R.F., 2001. Loss of noradrenaline transporter sites in frontal cortex of rats with acute (ischemic) liver failure. Neurochemistry International, 38(1), p.25-30. 
A. Michalak, C. Rose, J. Butterworth, R.F. Butterworth Neuroactive amino acids and glutamate (NMDA) receptors in frontal cortex of rats with experimental acute liver failure Hepatology, 24 (1996), pp. 908-913

M. Michalak, C. Rose, P.N.T. Buu, R.F. Butterworth Evidence for altered central noradrenergic function in experimental acute liver failure in the rat Hepatology, 27 (1998), pp. 362-368

N. Murakami, K. Saito, T. Kato, T. Nakamura, H. Moriwaki, Y. Muto Changes in brain monoamine metabolism in rats with acute ischemic hepatic failure under artificial cardiopulmonary management Gastroenterol. Jpn., 27 (1992), pp. 191-198

M.D. Norenberg The role of astrocytes in hepatic encephalopathy Neurochem. Pathol., 6 (1987), pp. 145-166

M.D. Norenberg Astrocyte responses to CNS injury J. Neuropath. Exp. Neurol., 53 (1994), pp. 213-220

G. Paxinos, C. Watson The Rat Brain In Stereotaxic CoordinatesAcademic Press, New York (1982)

y Shao, J. Sutin Expression of adrenergic receptors in individual astrocytes and motor neurons isolated from the adult rat brain Glia, 6 (1992), pp. 108-117

M. Swain, R.F. Butterworth, A.T. Blei Ammonia and related amino acids in the pathogenesis of brain edema in acute ischemic liver failure in rats Hepatology, 15 (1992), pp. 449-453

D. Tarver, R.P. Walt, A.A. Dunk, W.J. Jenkins, S. Sherlock Precipitation of hepatic encephalopathy by propranolol in cirrhosis Br. Med. J. Clin. Res. Ed., 287 (1983), p. 585

S.M. Tejani-Butt [ $\left.{ }^{3} \mathrm{H}\right]$ Nisoxetine: a radioligand for quantitation of norepinephrine uptake sites by autoradiography or by homogenate binding J. Pharmacol. Exp. Ther., 260 (1992), pp. 427-436

G.M. Tyce, C.A. Owen Jr. Dopamine and norepinephrine in the brain of hepatectomized rats Life Sciences, 22 (1978), pp. 781-786

R.H. Wiesner Does propranolol precipitate hepatic encephalopathy? J. Clin. Gastroenterol., 8 (1986), pp. 74-76

C. Yurdaydin, H. Hörtnagl, P. Steindl, C. Zimmermann, C. Pifl, E.A. Singer, E. Roth, P. Ferenci Increased serotoninergic and noradrenergic activity in hepatic encephalopathy in rats with thioacetamide-induced acute liver failure Hepatology, 12 (1990), pp. 695700

Michalak, A., Rose, C. \& Butterworth, R.F., 2001. Loss of noradrenaline transporter sites in frontal cortex of rats with acute (ischemic) liver failure. Neurochemistry International, 38(1), p.25-30. 